\title{
Role of miR-21 on vascular endothelial cells in the protective effect of renal delayed ischemic preconditioning
}

\author{
XIALIAN XU ${ }^{1-3}$, XIAOYAN JIAO ${ }^{1-3}$, NANA SONG ${ }^{1-3}$, WEILI LUO ${ }^{1-3}$, \\ MINGYU LIANG ${ }^{4}$, XIAOQIANG DING ${ }^{1-3}$ and JIE TENG ${ }^{1-3}$ \\ ${ }^{1}$ Department of Nephrology; ${ }^{2}$ Shanghai Institute of Kidney Disease and Dialysis; \\ ${ }^{3}$ Kidney and Blood Purification Laboratory of Shanghai, Zhongshan Hospital, Fudan University, Shanghai 200032, \\ P.R. China; ${ }^{4}$ Department of Physiology and Center of Systems Molecular Medicine, \\ Medical College of Wisconsin, Milwaukee, WI 53226, USA
}

Received January 19, 2016; Accepted April 25, 2017

DOI: $10.3892 / \mathrm{mmr} .2017 .6870$

\begin{abstract}
Vascular endothelial cells may serve crucial roles in the development of acute kidney injury (AKI). microRNA (miR)-21, which possesses a renal protective function has been found on vascular endothelial cells. The present study aimed to test the hypothesis that miR-21 may protect vascular endothelial cells against injury, which may contribute to the protective effects of renal delayed ischemic preconditioning (IPC). Preconditioned (15 min ischemia) or Sham mice (not clamped) were subjected to 35 min occlusion of bilateral renal pedicles 4 days following preconditioning or Sham treatment. Human umbilical vein endothelial cells (HUVECs) were treated with cobalt(II) chloride $\left(\mathrm{CoCl}_{2}\right)$ to establish an in vitro hypoxia model. Locked nucleic acid-modified anti-miR-21 or scrambled control oligonucleotides were transfected into cells or delivered into mice via tail vein injection $<1 \mathrm{~h}$ prior to IPC. Following $24 \mathrm{~h}$ of reperfusion or hypoxia, morphological and functional parameters, apoptosis and miR-21 and programmed cell death 4 (PDCD4) expression were assessed in vivo and in vitro. Treatment of HUVECs with $\mathrm{CoCl}_{2}$ led to an upregulation of miR-21 expression, a downregulation of PDCD4 protein expression and attenuation of apoptosis. Inhibition of miR-21 expression led to increased expression levels of PDCD4 protein and apoptosis in HUVECs. IPC attenuated renal IR injury in mice. The protective effect of IPC appeared to be dependent on upregulated miR-21 expression. IPC-induced upregulation of miR-21 expression also occurred in HUVECs, and IPC also led to reduced PDCD4 expression and vascular permeability in mouse kidneys. The effects of IPC were attenuated by the
\end{abstract}

Correspondence to: Professor Xiaoqiang Ding or Dr Jie Teng, Department of Nephrology, Zhongshan Hospital, Fudan University, 180 Fenglin Road, Shanghai 200032, P.R. China

E-mail: ding.xiaoqiang@zs-hospital.sh.cn

E-mail: teng.jie@zs-hospital.sh.cn

Key words: renal delayed ischemic preconditioning, renal ischemia/reperfusion, microRNA-21, apoptosis, vascular endothelial cells inhibition of miR-21; miR-21 expression attenuated damage in vascular endothelial cells, which may contribute to the protective effects of delayed IPC on renal IR injury. The present study suggested a novel target for the prevention and repair of $\mathrm{AKI}$ in the future.

\section{Introduction}

Renal ischemia/reperfusion (IR) injury is a major cause of acute kidney injury (AKI), the pathophysiology of which is considered to be associated with renal tubular epithelial cell injury (1). Vascular endothelial cells may be involved in determining vascular permeability, communicating with other cells and regulating vasomotion. In addition, vascular endothelial cells may serve crucial roles in the development of AKI. An injection of HUVECs can be implanted in the vascular bed of the renal peritubular capillaries and significantly improve renal function after I/R injury (2). It was hypothesized that HUVECs may possess some characteristics or functions of renal peritubular microvascular endothelial cells and thus HUVECs were used for in vitro study. Delayed ischemic preconditioning (IPC) is a brief, sublethal episode of ischemia that protects certain organs against subsequent lethal ischemic insult and is thought to be an endogenous mechanism of preserving organ function. The beneficial effects of delayed IPC have been confirmed in the kidneys of rats and mice (3-5); however, the role of renal vascular endothelial cells in delayed IPC has not previously been investigated.

microRNAs (miRNAs) are endogenous, short (18-22 nucleotides) RNA molecules that may be involved in the physiological functions of the kidneys and in the pathological processes of renal disease. Several miRNAs, including miR-200, miR-21 and miR-133, have been previously demonstrated to be associated with the protective effects of IPC on IR injury (6,7). Our previous study demonstrated that IPC significantly increased the expression of miR-21 in the mouse kidney $24 \mathrm{~h}$ following IR. Knockdown of miR-21, combined with IPC, significantly exacerbated subsequent renal IR injury (8). Other studies have demonstrated that miR-21 is expressed in vascular endothelial cells $(9,10)$, and that programmed cell death 4 (PDCD4) is a proapoptotic target gene of miR-21 (8). The present study 
focused on vascular endothelial cells and hypothesized that the protective role of miR-21 in renal delayed IPC may be associated with reduced endothelial cell apoptosis by targeting PDCD4.

\section{Materials and methods}

Mouse models of delayed renal IPC and IR. A total of 60 male C57BL/6 mice (weight, 20-23 g; age, 6-7 weeks) were housed in the Animal Center of Zhongshan Hospital of Fudan University at $24-25^{\circ} \mathrm{C}, 5 \% \mathrm{CO}_{2}$, free access to food and water, and $16-\mathrm{h}$ light/8-h dark cycle. The mice were anesthetized intraperitoneally with $1 \%$ pentobarbital $(50 \mathrm{mg} / \mathrm{kg}$; Sigma-Aldrich, Merck KGaA, Darmstadt, Germany). Following midline laparotomy, the bilateral renal pedicles were clamped for $15 \mathrm{~min}$ using micro-serrefine clips (Fine Science Tools, Inc., Foster City, CA, USA) to induce IPC. Mice were maintained at $35-37^{\circ} \mathrm{C}$ and the abdominal cavity was hydrated with saline-moistened gauze. Mice in the IPC + IR group were subjected to $35 \mathrm{~min}$ bilateral kidney ischemia 4 days post-IPC, followed by reperfusion for $24 \mathrm{~h}$. Mice in the Sham group underwent the same surgical procedures, except that the renal pedicles were not clamped (no IPC). Following treatment, the mice were anesthetized intraperitoneally with $1 \%$ pentobarbital $(50 \mathrm{mg} / \mathrm{kg})$ at $24 \mathrm{~h}$ after reperfusion, and then the blood samples were taken by cardiac puncture and the kidneys collected; one kidney was snap-frozen in liquid nitrogen for protein and RNA isolation followed by transference to a $-80^{\circ} \mathrm{C}$ freezer, and the other kidney was fixed for histological analysis. Serum creatinine (SCr) was measured as previously described by a Quantichrom creatinine Assay kit (BioAssay Systems, Hayward, CA, USA) (8). The study was approved by the ethics committee of Zhongshan Hospital of Fudan University (Shanghai, China).

Histological analysis of renal injury and immunohistochemical staining. Kidney tissues were fixed in $10 \%$ neutral-buffered formalin at room temperature for $24 \mathrm{~h}$ and embedded in paraffin. Tissues were sectioned $(4 \mu \mathrm{m})$, deparaffinized and stained with periodic acid-Schiff counterstained with alum hematoxylin. Histopathological changes were examined in a blinded manner by scoring tubular cell necrosis or swelling, interstitial infiltration by multinucleated cells, tubular casts and brush border loss; sections were scored according to the severity of changes on a semi-quantitative scale: No injury (0); mild, $<25 \%$ (1); moderate, $<50 \%$ (2); severe, $<75 \%$ (3); and very severe, $>75 \%$ (4). For immunohistochemistry, kidney sections were deparaffinized in dimethylbenzene twice, dehydrated in gradient ethanol and endogenous peroxidase activity was eliminated by $3 \% \mathrm{H}_{2} \mathrm{O}_{2}$ incubation at room temperature for $30 \mathrm{~min}$. The sections were blocked with $10 \%$ goat serum (Sigma-Aldrich, Merck KGaA) for 20 min at room temperature and incubated with monoclonal rat anti-mouse CD31 antibody (ab7388, 1:50; Abcam, Cambridge, MA, USA) overnight at $4^{\circ} \mathrm{C}$. Antibody dilution and washing steps were performed with PBS. The secondary antibody incubation and staining was carried out by GTVision II Immunohistochemistry Detection System/Mo\&Rb (GK500611A; Gene Tech Biotechnology Co., Ltd., Shanghai, China) according to the manufacturer's protocol.

miR-21 in situ hybridization (ISH). ISH was performed on the formalin-fixed paraffin-embedded kidney sections $(4 \mu \mathrm{m})$ by
microRNA ISH Optimization kit 2 (Exiqon A/S, Vedbaek, Denmark) with 5'- and 3'-digoxigenin (DIG)-labeled miR-21 probes and $\mathrm{U} 6$ as a positive control, according to the manufacturer's protocols, with minor modifications. Briefly, tissue sections were deparaffinized in xylene and rehydrated using an ethanol gradient. Sections were treated with proteinase $\mathrm{K}$ $\left(20 \mathrm{mg} / \mathrm{ml}\right.$ ) for $10 \mathrm{~min}$ at $37^{\circ} \mathrm{C}$ and subsequently incubated with hybridization buffer at room temperature for $30 \mathrm{~min}$. The probes were diluted in hybridization buffer $(40 \mathrm{nM}$ for miR-21 and $1 \mathrm{nM}$ for U6) and preheated at $90^{\circ} \mathrm{C}$ for $5 \mathrm{~min}$ to linearize prior to adding to the slides (50 $\mu \mathrm{l} /$ tissue section). Following incubation at $53^{\circ} \mathrm{C}$ for $2 \mathrm{~h}$, slides were rinsed twice (5 min each) in 5X saline sodium citrate (SSC), 1X SSC and $0.1 \mathrm{X} \mathrm{SSC}$ at $53^{\circ} \mathrm{C}$, followed by washes with PBS-Tween-20 $(0.1 \%)$, and blocking with sheep serum (2\%; Jackson ImmunoResearch Laboratories, Inc., West Grove, PA, USA) for $30 \mathrm{~min}$ at $37^{\circ} \mathrm{C}$. Slides were subsequently incubated with 1:800 anti-DIG alkaline phosphatase antibody (11 093274 910; Roche Applied Science, Rotkreuz, Switzerland) for $1 \mathrm{~h}$ at room temperature, followed by incubation in nitro blue tetrazolium/5-bromo-4-chloro-3-indolyl phosphate (11 697 471 001; Roche Applied Science) diluted in double-distilled $\mathrm{H}_{2} \mathrm{O}$ for $2 \mathrm{~h}$ at $34^{\circ} \mathrm{C}$. Slides were rinsed with alkaline phosphatase stop solution to halt the color development, prior to dehydration with 70, 96 and $99.99 \%$ ethanol in sequence ( 1 min followed by immersing 10 times for each ethanol), clearing with dimethylbenzene for 5 min and mounting in Eukitt $^{\circledR}$ (Sigma-Aldrich; Merck KGaA) at room temperature. The tissue was visualized by microscope (Leica DM6000 B; Leica Microsystems GmbH, Wetzlar, Germany) and images captured and analyzed by Leica Application Suite software version 4.5 (Leica Microsystems $\mathrm{GmbH}$ ).

Assessment of renal vascular protein leakage using Evans blue dye. Evans blue dye was used to assess vascular leakage to evaluate renal microvascular permeability as previously described (11). Mice were injected intravenously with Evans blue dye ( $2 \mathrm{ml} / \mathrm{kg}$; Sigma-Aldrich; Merck KGaA) $30 \mathrm{~min}$ prior to sacrifice. Following sacrifice, mice were perfused with PBS through the left ventricle to completely eliminate blood. The kidneys were weighed and subsequently homogenized in $1 \mathrm{ml}$ pure formamide (Sigma-Aldrich; Merck $\mathrm{KGaA}$ ) and incubated at $55^{\circ} \mathrm{C}$ for $18 \mathrm{~h}$. The supernatant was collected following centrifugation $(10,000 \mathrm{x} \mathrm{g}$ for $30 \mathrm{~min}$ at room temperature). The amount of Evans blue dye in the supernatant was analyzed by measuring absorbance at $620 \mathrm{~nm}$. Results were calculated from a standard curve of Evans blue dye and expressed as the concentration of Evans blue dye $(\mu \mathrm{g}) /$ kidney weight $(\mathrm{g})$.

Cell culture and cobalt (II) chloride $\left(\mathrm{CoCl}_{2}\right)$ treatment. HUVEC were obtained from American Type Culture Collection (Manassas, VA, USA) and cultured in endothelial cell medium with 5\% fetal bovine serum (Sciencell Research Laboratories, Inc., Carlsbad, CA, USA) at $37^{\circ} \mathrm{C}$ with $95 \%$ air and $5 \% \mathrm{CO}_{2}$. HUVECs at $60-70 \%$ confluence were exposed to $150 \mu \mathrm{M} \mathrm{CoCl}_{2}$ for $24 \mathrm{~h}$ under $37^{\circ} \mathrm{C}$ to mimic hypoxia or placed in fresh normal medium as a control as previously described (12). Following $\mathrm{CoCl}_{2}$ incubation, the cells were harvested for RNA, protein extraction or flow cytometry. 
A

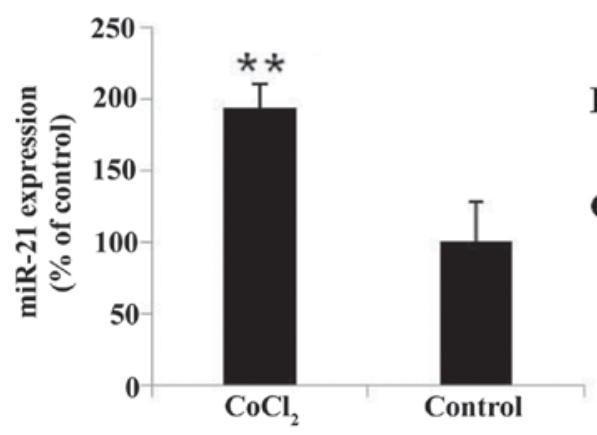

B

PDCD4
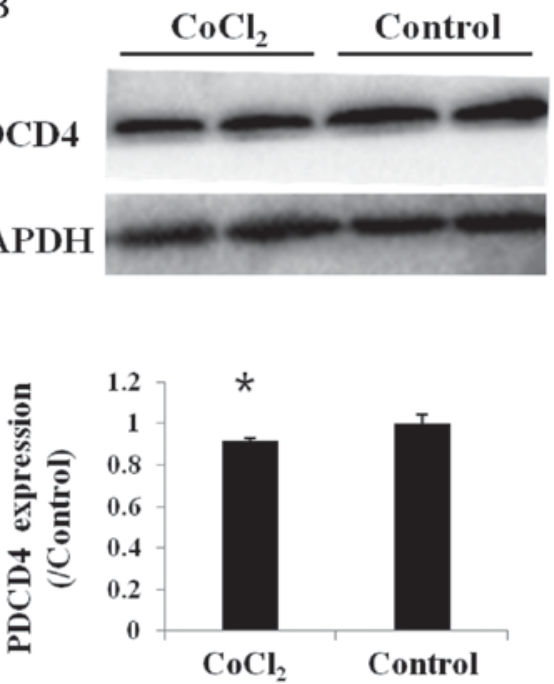

Figure 1. Hypoxia induces miR-21 expression in HUVECs. (A) miR-21 was upregulated by $\mathrm{CoCl}_{2}$ treatment at $150 \mu \mathrm{M}$ for $24 \mathrm{~h}$ in $\mathrm{HUVECs}$. (B) Decreased expression of PDCD4 protein was observed in HUVECs following $\mathrm{CoCl}_{2}$ treatment. Data are presented as the mean \pm standard error of the mean. $\mathrm{n}=3$ per group; ${ }^{*} \mathrm{P}<0.05$ and ${ }^{* *} \mathrm{P}<0.01$ vs. control. $\mathrm{CoCl}_{2}$, cobalt chloride; HUVECs, human umbilical vein endothelial cells; miR-21, microRNA-21; PDCD4, programmed cell death protein 4.

In vitro and in vivo use of locked nucleic acid(LNA)-modified anti-miR-21 oligonucleotides. LNA-modified anti-miR-21 oligonucleotides (Exiqon A/S) were used to suppress miR-21 expression in both in vitro and in vivo experiments with the scrambled oligonucleotides (Exiqon $\mathrm{A} / \mathrm{S}$ ) as the control. The sequence of the anti-miR-21 and scrambled control are as follows: LNA anti miR-21 5'-FAM-TCAGTCTGATAAG CT-3'; scrambled control: 5'-FAM-ACGTCTATACGCC CA-3'. HUVECs at $80-90 \%$ confluence $\left(1 \times 10^{6} /\right.$ well in a 6 well plate) were transfected with anti-miR-21 and scrambled controloligonucleotides (100 nM), using Lipofectamine ${ }^{\circledR} 2000$ (Invitrogen; Thermo Fisher Scientific, Inc., Waltham, MA, USA) according to the manufacturer's protocols. The final concentration of $\mathrm{LNA}^{\mathrm{TM}}$ microRNA inhibitors (LNA-oligos) was decided according to the suggested concentration from LNA-oligos and Lipofectamine ${ }^{\circledR} 2000$ from the manufacturer combined with the dose from a previous study (13). Briefly, LNA mix was incubated in the Lipofectamine ${ }^{\circledR} 2000$ mix for $20 \mathrm{~min}$ at room temperature before pouring into dishes. The transfection medium was replaced with the regular medium $4 \mathrm{~h}$ post-transfection. Following $20 \mathrm{~h}$ incubation, cells were treated with $\mathrm{CoCl}_{2}$. LNA-modified anti-miR-21 and scrambled control oligonucleotides used for in vivo suppression experiments were administered by intravenous tail vein injection $(10 \mathrm{mg} / \mathrm{kg}$ body weight $)<1 \mathrm{~h}$ prior to ischemia surgery (8).

TaqMan reverse transcription-quantitative polymerase chain reaction ( $R T-q P C R)$. Total RNA from kidney tissue (1/4 kidney) and cells with $80-90 \%$ confluence in $3.5 \mathrm{~cm}$ dishes was isolated using TRIzol (Invitrogen; Thermo Fisher Scientific, Inc.) according to the manufacturer's protocol. The RNA purity was determined according to the ratio of A260/A280 (1.8-2.0). RT-qPCR of miR-21 were performed with the TaqMan MicroRNA Reverse Transcription kit (Applied Biosystems; Thermo Fisher Scientific, Inc.) for RT and then the TaqMan(R) Universal PCR Master Mix (Applied
Biosystems) for cDNA amplification according to the manufacturer's protocol (14). U6 was used as internal control to normalize miRNA expression. Ambion ${ }^{\circledR}$ (Thermo Fisher Scientific) RT and PCR primers of miR-21 (has-miR-21; ID 000397) and U6 (U6 snRNA ID 001973) are special for TaqMan ${ }^{\circledR}$ MicroRNA Assays. The program of $16^{\circ} \mathrm{C}$ for $30 \mathrm{~min}, 42^{\circ} \mathrm{C}$ for $30 \mathrm{~min}$ and $85^{\circ} \mathrm{C}$ for $5 \mathrm{~min}$ was used for RT. qPCR was conducted at $95^{\circ} \mathrm{C}$ for $10 \mathrm{~min}$, followed by 40 cycles of $95^{\circ} \mathrm{C}$ for $15 \mathrm{sec}$ and $60^{\circ} \mathrm{C}$ for $1 \mathrm{~min}$ in the Applied Biosystems ${ }^{\circledR} 7500$ Real-Time PCR Systems (Thermo Fisher Scientific, Inc.). The 7500 software version 2.0.6 was used for analysis. The expression level of miR-21 was analyzed as described previously (8) and the $2^{-\Delta \Delta \mathrm{Cq}}$ method was used for normalization (15).

Western blot analysis. The cells were lysed by cold RIPA lysis buffer (with $1 \mathrm{mM}$ phenylmethylsulfonyl fluoride; KeyGen Biotech Co., Ltd., Nanjing, China). Half of one kidney was frozen and ground in liquid nitrogen, then disrupted in cold lysis buffer. Supernatants were collected after centrifuged. The BCA method of protein quantification was used with the kit (KeyGen Biotech Co., Ltd.). Protein samples (40 $\mu \mathrm{g}$ per lane) were separated by $10 \%$ SDS-PAGE and transferred to a polyvinylidene difluoride membrane. The describe membrane was blocked with $5 \%$ nonfat milk for $1 \mathrm{~h}$ at room temperature, followed by incubation with primary antibodies against PDCD4 (rabbit polyclonal; NBP1-76738; 1:1,000; Novus Biologicals, LLC, Littleton, CO, USA) or $\beta$-actin (mouse monoclonal; 1:1,000; Abcam) overnight at $4^{\circ} \mathrm{C}$. The secondary antibodies included horseradish peroxidase-conjugated anti-rabbit or anti-mouse immunoglobulin G (sc-2372 for anti-rabbit and sc-2005 for anti-mouse; 1:5,000; Santa Cruz Biotechnology, Inc.) and were used for incubation for $1.5 \mathrm{~h}$ at room temperature. Protein bands were developed with ECL Western Blotting Detection Reagents (Thermo Fisher Scientific, Inc.) according to the manufacturer's protocol. The results were normalized to the protein levels of $\beta$-actin. 

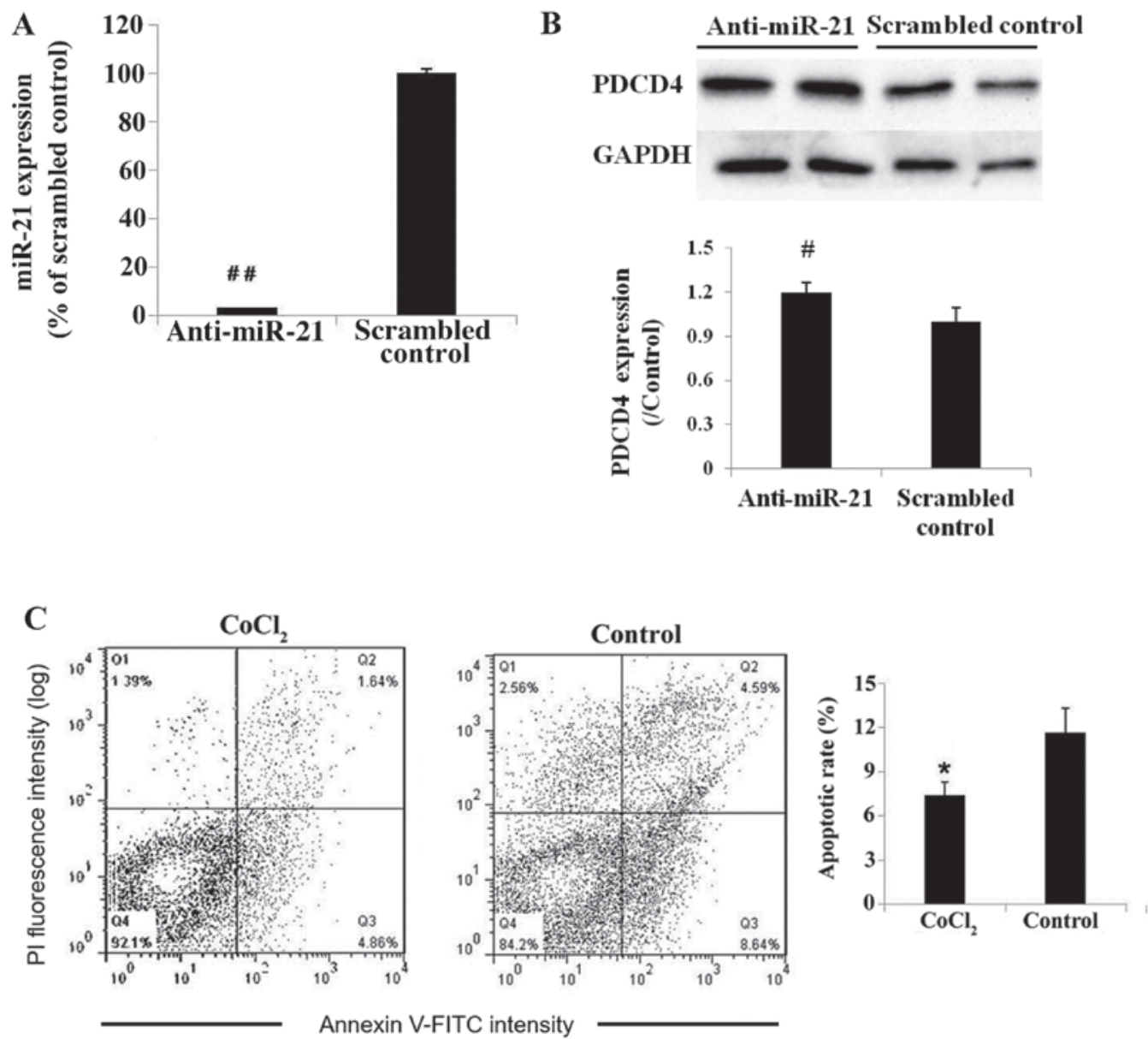

\section{D}
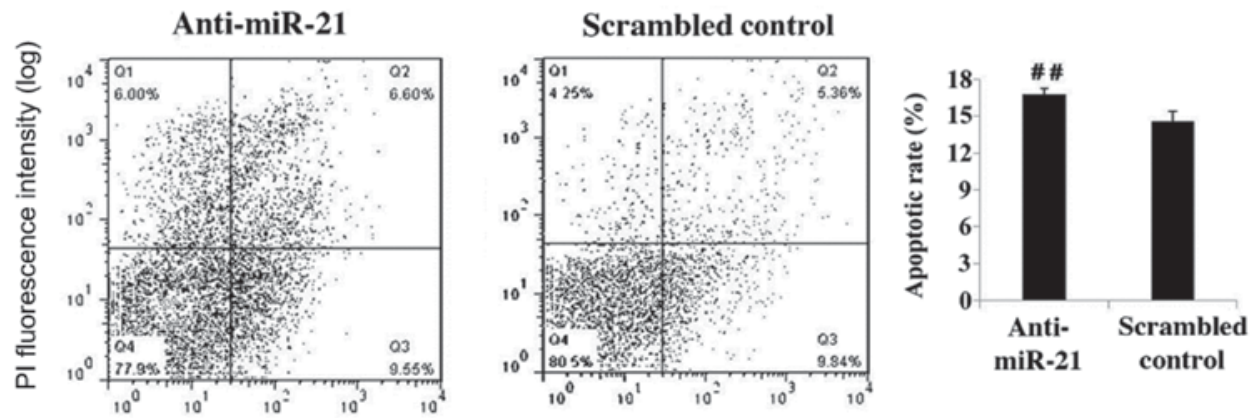

Figure 2. Knockdown of miR-21 increases PDCD4 expression and apoptosis of HUVECs in hypoxic conditions. (A) Expression of miR-21 was suppressed by the locked nucleic acid-modified anti-miR-21 oligonucleotide in hypoxic $\left(\mathrm{CoCl}_{2}\right.$-treated) HUVECs compared with scrambled control-treated cells. (B) Western blot analysis demonstrated that anti-miR-21 exposure increased PDCD4 protein expression in $\mathrm{CoCl}_{2}$-treated HUVECs compared with the scrambled control group. (C) Apoptosis was significantly decreased in HUVECs treated with $\mathrm{CoCl}_{2}$. (D) Anti-miR-21 treatment increased apoptosis of hypoxic HUVECs. Data are presented as the mean \pm standard error of the mean. $\mathrm{n}=6$ per group; ${ }^{*} \mathrm{P}<0.05 \mathrm{vs}$. control; ${ }^{\#} \mathrm{P}<0.05$ and ${ }^{\# \#} \mathrm{P}<0.01$ vs. scrambled control; $\mathrm{CoCl}_{2}$, cobalt chloride; HUVECs, human umbilical vein endothelial cells; miR-21, microRNA-21; PDCD4, programmed cell death protein 4.

Flow cytometry analysis for apoptosis. Apoptosis in cultured cells was measured by flow cytometry with the Annexin V-FITC/PI Apoptosis Detection kit (KeyGen Biotech Co., Ltd.) according to the manufacturer's protocol. At $24 \mathrm{~h}$ following $\mathrm{CoCl}_{2}$ treatment with or without LNA-oligos, the cells were harvested, washed with PBS and stained with Annexin V-fluorescein isothiocyanate (FITC) and propidium iodide (PI) for $10 \mathrm{~min}$ in a dark environment, and detection was performed by BD FACSAria ${ }^{\mathrm{TM}}$ II Flow Cytometer (BD Biosciences, San Jose, CA, USA). The data from flow cytometry was analyzed by FlowJo software version 7.6.1 (FlowJo
LLC, Ashland, OR, USA). Early apoptotic cells exhibited Annexin V-FITC+/PI- staining patterns, whereas late apoptotic cells exhibited Annexin V-FITC+/PI+ staining patterns in the flow cytometry plots. All experiments were performed in triplicate.

Statistical analysis. SPSS version 16.0 (SPSS, Inc., Chicago, IL, USA) was used for statistical analysis. Data were analyzed using the unpaired Student's t-test when comparing between 2 groups and one-way analysis of variation with Tukey's multiple comparison when comparing $>2$ groups. RT-qPCR 

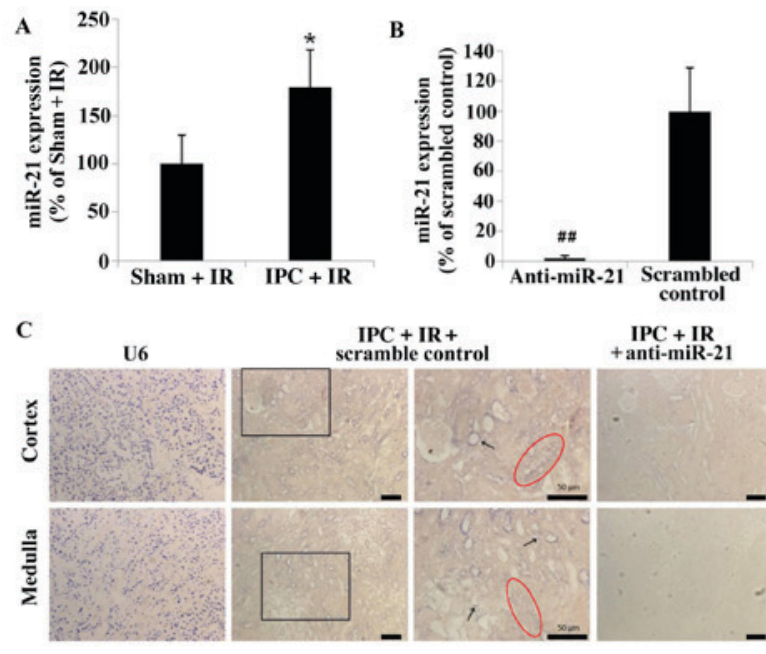

$\underset{\text { IPC }+ \text { IR }+}{\text { scramble control }}$

control

CD31

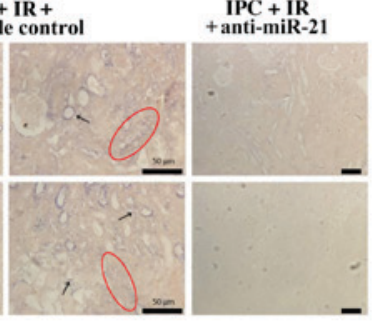

D miR-21
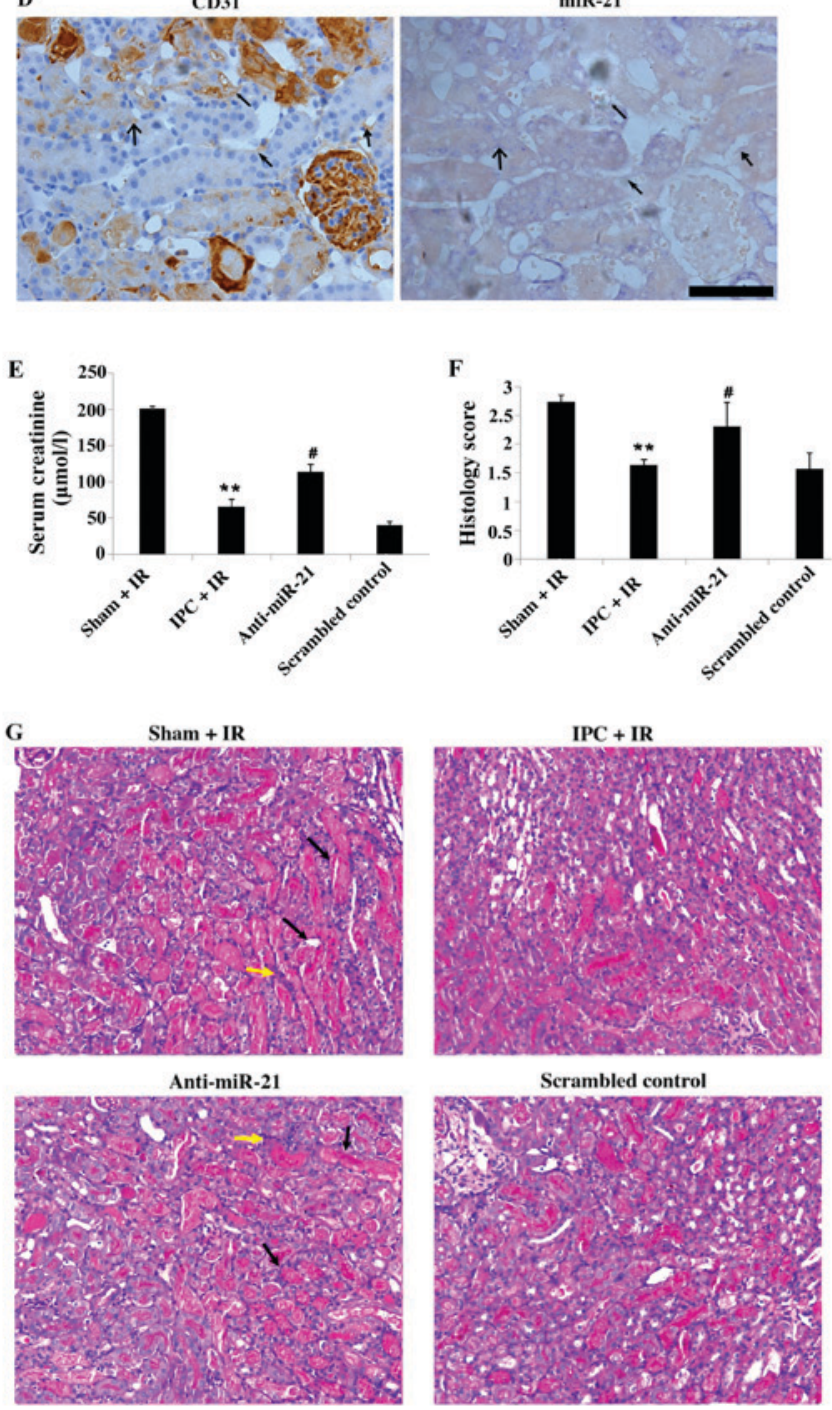

Figure 3. Delayed IPC increased miR-21 expression in renal tubular and in endothelial cells, which was inhibited by locked nucleic acid-modified anti-miR-21 oligonucleotide treatment. (A) miR-21 expression $24 \mathrm{~h}$ following IR was increased in kidneys exposed to IPC compared with Sham + IR mice. (B) Expression of miR-21 in the renal tissue $24 \mathrm{~h}$ following IR was inhibited by treatment with anti-miR-21 administered at the time of IPC, compared with mice treated with the scrambled control oligonucleotides. (C) Representative images of U6 (positive control) and miR-21 expression in mouse kidney sections by in situ hybridization. The increase of miR-21 expression was notable in vascular endothelial cells (arrows) of IPC + IR + scrambled control-treated mice in addition to the renal tubular epithelial cells (red circle). Magnification, x20; scale bar, $50 \mu \mathrm{m}$. (D) miR-21 expression in vascular endothelial cells, which were marked by CD31 staining and is indicated by the similar shaped arrows in the two images. (E) Serum creatinine and (F) histology score $24 \mathrm{~h}$ following IR were attenuated by delayed IPC, wherease miR-21 knockdown in mice exposed to delayed IPC significantly worsened renal IR injury. (G) Histopathological changes of mice kidney sections from each group. Representative periodic acid-Schiff-stained micrographs in the corticomedullary junction. Magnification, $\mathrm{x} 20$. Black arrow indicates cast formation and yellow arrow indicates infiltration of inflammatory cells. Data are presented as the mean \pm standard error of the mean. $\mathrm{n}=6$ per group; ${ }^{*} \mathrm{P}<0.05$ and ${ }^{* *} \mathrm{P}<0.01$ vs. Sham + IR group; ${ }^{\#} \mathrm{P}<0.05$ and ${ }^{\# \#} \mathrm{P}<0.01$ vs. scrambled control group. IPC, ischemic preconditioning; IR, ischemia/reperfusion; miR-21, microRNA-21; U6, U6 small nuclear RNA. 

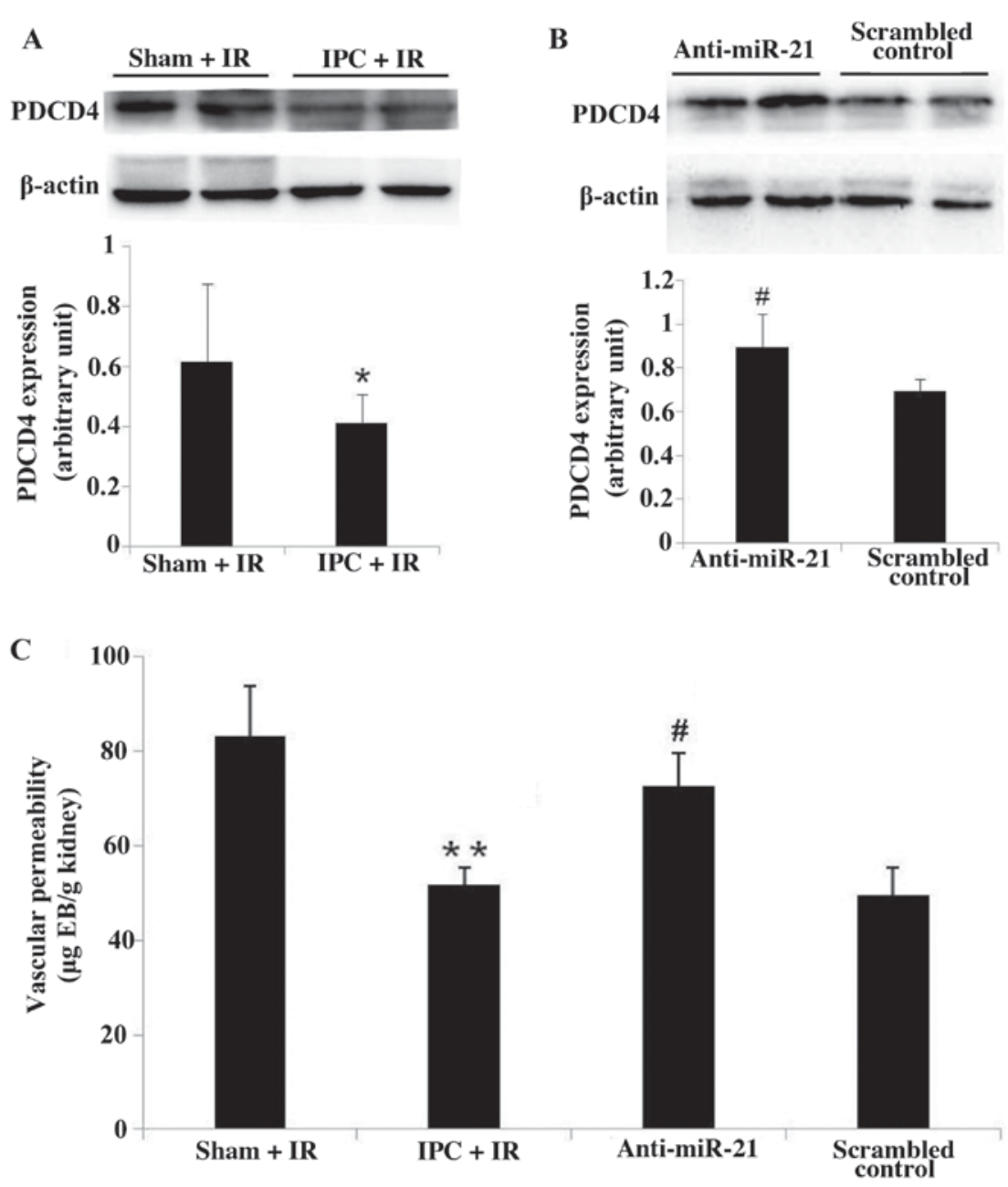

Figure 4. Knockdown of miR-21 exacerbates IR injury in mice kidneys following delayed IPC and IR by upregulation of PDCD4 expression, and exacerbates damage of microvascular endothelial cells. (A) PDCD4 protein expression was decreased in mice kidneys exposed to delayed IPC and IR. (B) miR-21 knockdown resulted in upregulation of PDCD4 protein expression. (C) Delayed IPC significantly attenuated apoptosis of vascular endothelial cells as indirectly determined by microvascular permeability $24 \mathrm{~h}$ after IR, whereas locked nucleic acid-modified anti-miR-21 oligonucleotide treatment exacerbated Evans blue dye leakage from renal vascular cells. Data are presented as the mean \pm standard error of the mean. $\mathrm{n}=5-6$ per group; ${ }^{*} \mathrm{P}<0.05$ and ${ }^{* *} \mathrm{P}<0.01$ vs. Sham $+\mathrm{IR}$ group; ${ }^{*} \mathrm{P}<0.05$ vs. scrambled control group. IPC, ischemic preconditioning; IR, ischemia/reperfusion; miR-21, microRNA-21; PDCD4, programmed cell death protein 4.

data are presented as a percentage of the control since data from multiple PCR plates were combined. For these data, statistical analysis was performed on the original data before conversion to percentage values. $\mathrm{P}<0.05$ was considered to indicate a statistically significant difference. Data are presented as the mean \pm standard error of the mean.

\section{Results}

$\mathrm{CoCl}_{2}$ treatment affects the expression of miR-21 and PDCD4 protein in HUVECs. Our previous study demonstrated that hypoxic conditions were able to induce the expression of miR-21 in human renal epithelial cells (13). The present study used $\mathrm{CoCl}_{2}$ to mimic hypoxia in vitro, and HUVECs treated with $\mathrm{CoCl}_{2}$ for $24 \mathrm{~h}$ exhibited a significant upregulation of miR-21 expression compared with the control group (193.44 $\pm 16.32 \%$ of the control; $\mathrm{P}<0.01$; Fig. 1A). In addition, the expression of PDCD4 protein in the $\mathrm{CoCl}_{2}$ and control groups was investigated by western blot analysis. PDCD4 protein expression was significantly reduced compared with the control group $(\mathrm{P}<0.05$; Fig. 1B). 
control or anti-miR-21 oligonucleotides were administered to mice through the tail vein prior to IPC surgery; treatment with anti-miR-21 significantly reduced the expression of miR-21 in the kidney $24 \mathrm{~h}$ following the second IR compared with the scrambled control group $(2.43 \pm 0.71 \%$ of the scrambled control group; $\mathrm{P}<0.01$; Fig. $3 \mathrm{~B}$ ). ISH for miR-21 expression was examined in the cortex and medulla in the kidney under all experimental conditions, and the results revealed that the expression of miR-21 was increased in IPC + IR mice that were co-treated with scrambled control, and suppressed with anti-miR-21 treatment (Fig. 3C). The result of ISH in the scrambled control group shown that miR-21 could express in the vascular endothelial cells (arrows in Fig. 3C) in addition to the tubular epithelial cells (circles in Fig. 3C); however, this pattern of miR-21 expression was not observed in either region in IPC + IR mice treated with anti-miR-21. The expression of U6 positive control is shown in the anti-scrambled control. To further identify the distribution of miR-21 expression in vascular endothelial cells, immunohistochemical staining of CD31 for vascular endothelial cells and ISH for miR-21 in two serial sections was performed. As demonstrated in Fig. 3D, the positive expression area of CD31 and miR-21 are similar as indicated by similar shaped arrows in the two images.

Delayed IPC significantly attenuated IR-induced renal dysfunction, as demonstrated by the renal function and histological damage observed (Fig. 3E-G). Compared with the Sham + IR group, IPC + IR mice exhibited a significant decrease in $\mathrm{SCr}(\mathrm{P}<0.01$; Fig. $3 \mathrm{E})$ and histology score $(\mathrm{P}<0.01$; Fig. 3F). However, treatment with anti-miR-21 reversed the protective effect of IPC in IR mice: The anti-miR-21 group had significantly increased $\mathrm{SCr}$ and histology score compared with the scrambled control ( $\mathrm{P}<0.05$; Fig. $3 \mathrm{E}$ and $\mathrm{F}$, respectively) and exhibited characteristics of acute tubulointerstitial damage similar to that observed in the Sham + IR group, including massive tubular epithelial cell necrosis or swelling, tubular casts and inflammatory cell infiltration (Fig. 3G).

miR-21 knockdown may increase vascular endothelial cell apoptosis by increasing PDCD4 expression. The expression of PDCD4 protein was examined in mice from all groups. PDCD4 protein expression was significantly downregulated in IPC + IR mice compared with Sham + IR mice $(\mathrm{P}<0.05$; Fig. 4A), whereas PDCD4 protein expression was significantly upregulated by in IPC + IR mice treated with anti-miR-21 compared with mice in the scrambled control group $(\mathrm{P}<0.05$; Fig. 4B), which was consistent with the suggestion that PDCD4 may be targeted by miR-21 (16). Renal microvascular permeability was measured by Evans blue dye leakage, and was assessed to indirectly evaluate apoptosis of vascular endothelial cells. The amount of Evans blue dye in the kidney of IPC + IR mice was significantly lower compared with Sham + IR mice $(\mathrm{P}<0.01$; Fig. $4 \mathrm{C})$. In addition, IPC + IR mice that received anti-miR-21 treatment exhibited a significant increase in the amount of Evans blue dye in the kidney compared with IPC + IR mice treated with scrambled control $(\mathrm{P}<0.05$; Fig. 4C), which suggested an increase in apoptosis of vascular endothelial cells in the kidney. The results indicated that miR-21 may attenuate vascular endothelial cell apoptosis by targeting PDCD4 and may serve a role in the protective effects of delayed IPC.

\section{Discussion}

The present study, to the best of our knowledge, is the first to focus on the involvement of vascular endothelial cells in renal delayed IPC. Tubular epithelial cells had been considered to the primarily target of renal ischemic insults (17), whereas the functional role of endothelial cells has received less attention. The renal microvascular endothelium has been reported to serve a vital role in the process of renal IR injury (18). It has been previously demonstrated that injury or apoptosis of the vascular endothelial cells may contribute to functional impairment of peritubular microcirculation, which triggers ischemic AKI (19-21). The present study hypothesized that the loss of barrier function may reflect endothelial cell apoptosis in the mouse kidney. A previous study demonstrated that the activation of caspase-3 protein, a biomarker for endothelial cell apoptosis, was consistent with increased microvascular permeability following ischemic injury, although they did not observe apoptosis by TUNEL staining (22). Owing to the rapid clearance of apoptotic cells and the moderate sensitivity of the TUNEL reaction in ischemic kidney tissue, the potential for positive apoptosis of endothelial cell to be observed by TUNEL is low. Therefore, the present study opted to indirectly evaluate apoptosis injury of microvascular endothelial cells by microvascular permeability assessment. Previous reports have indicated that the improvement of endothelial cells function by exogenous VEGF-121 or lecithinized superoxide dismutase, preserving renal microvessel structure or increasing free radical scavenging, may protect against IR injury and improve the prognosis of the AKI $(23,24)$. The present study hypothesized that the protective mechanism of renal hypoxic/ischemic intolerance may be associated with the antiapoptotic ability of renal vascular endothelial cells. However, the increased permeability of microvascular endothelial cells in this study may also have been the result of tubular epithelial cell injury and the resultant inflammation; which is a limitation of the present study.

miR-21 is an important antiapoptotic miRNA (25). Certain studies have suggested that miR-21 expression may be increased in cells tolerant to hypoxia and may be protective against hypoxia $(13,26,27)$. In tumor cells (ovarian or mammary carcinoma cell lines), miR-21 expression has been demonstrated to be induced through the Akt-2 pathway in hypoxic conditions and miR-21 expression promoted tumor resistance (28). Our previous study demonstrated that miR-21 expression was elevated by hypoxia $\left(2 \% \mathrm{O}_{2}\right.$ and $\left.\mathrm{CoCl}_{2}\right)$ treatment in human renal epithelial cells (8). The present study demonstrated that optimal hypoxia, that causing the least cell injury, may have decreased vascular endothelial cell apoptosis, consistent with the overexpression of miR-21 in HUVECs in vitro. Knockdown of miR-21 in hypoxic vascular endothelial cells led to a potential increase in apoptosis. PDCD4 was previously demonstrated to be a direct target of miR-21 (16), and miR-21 was reported to inhibit apoptosis by downregulating PDCD4 expression in the heart (29), cultured mouse tubular epithelial cells (30) and in mouse kidneys (8). Although the present study confirmed the antiapoptotic mechanism of miR-21 targeting PDCD4 in HUVECs in vitro, it is likely that the effect of miR21-PDCD4 pathway is partly from the endothelial cell since this pathway was confirmed in 
the tubular epithelial cells (30). In addition, phosphatase and tensin homolog deleted on chromosome 10 (PTEN) (31), Fas ligand (27) and tropomyosin 1 (32) are inhibited by miR-21, which leads to tolerance to cellular apoptotic signals. We aim to investigate other miR-21 target genes in endothelial cells in the future.

Delayed IPC has been confirmed to be protective against renal IR injury in the rodent kidney $(8,33)$, and miRNAs have been previously demonstrated to be involved in the protective mechanism of IPC $(8,34)$. A protective effect of miR-21 was reported in cardiac IPC $(29,34,35)$; these studies reported that IPC increased miR-21 expression, which was accompanied by reduced apoptosis in the border between the infarcted and noninfarcted areas, and decreased infarct size. Another study demonstrated that increased miR-21 expression was most significant in the rat cerebral cortex $24 \mathrm{~h}$ post-IPC (14). Our previous study reported the protective role of miR-21 in renal delayed IPC, which was associated with decreased apoptosis of renal tubular epithelial cells (8). It has also been reported that high expression of miR-21 occurred in vascular endothelial cells $(36,37)$. In addition, miR-21 was demonstrated to be significantly upregulated in vascular walls following balloon injury (9). The present study hypothesized that miR-21 expression in microvascular endothelial cells may contribute to the protection of renal delayed IPC against IR injury by attenuating injury of endothelial cells. The results suggested that knockdown of miR-21 can increase the damage to microvascular endothelial cells induced by renal IR injury 4 days after 15 min ischemic pretreatment, which attenuated the protection of delayed IPC. As multiple pathways have been implicated in the protective mechanism of renal delayed IPC, including a series of protective mediators and/or effectors, such as c-Jun N-terminal kinase, hypoxia-inducible factor, inducible nitric oxide synthase and heat shock protein $27(4,5)$, it is not unexpected that the knockdown of miR-21 had only a modest effect on the preconditioning effects in the present study.

In conclusion, renal protection conferred by delayed IPC may potentially be mediated by several mechanisms in different types of renal cells. The present study demonstrated that delayed IPC provided renal protection against IR injury by attenuating damage of renal microvascular endothelial cells, which may be partly attributed to miR-21.

\section{Acknowledgements}

This study was supported by the National Natural Science Foundation of China (grant no. 81300570) and the Foundation of Zhongshan Hospital grant.

\section{References}

1. Bonventre JV and Yang L: Cellular pathophysiology of ischemic acute kidney injury. J Clin Invest 121: 4210-4221, 2011.

2. Brodsky SV, Yamamoto T, Tada T, Kim B, Chen J, Kajiya F and Goligorsky MS: Endothelial dysfunction in ischemic acute renal failure: Rescue by transplanted endothelial cells. Am J Physiol Renal Physiol 282: F1140-F1149, 2002.

3. Jiang SH, Liu CF, Zhang XL, Xu XH, Zou JZ, Fang Y and Ding XQ: Renal protection by delayed ischaemic preconditioning is associated with inhibition of the inflammatory response and NF-kappaB activation. Cell Biochem Funct 25: 335-343, 2007.
4. Joo JD, Kim M, D'Agati VD and Lee HT: Ischemic preconditioning provides both acute and delayed protection against renal ischemia and reperfusion injury in mice. J Am Soc Nephrol 17: 3115-3123, 2006.

5. Park KM, Chen A and Bonventre JV: Prevention of kidney ischemia/reperfusion-induced functional injury and JNK, p38, and MAPK kinase activation by remote ischemic pretreatment. J Biol Chem 276: 11870-11876, 2001.

6. Salloum FN, Yin C and Kukreja RC: Role of microRNAs in cardiac preconditioning. J Cardiovasc Pharmacol 56: 581-588, 2010.

7. Lee ST, Chu K, Jung KH, Yoon HJ, Jeon D, Kang KM, Park KH, Bae EK, Kim M, Lee SK and Roh JK: MicroRNAs induced during ischemic preconditioning. Stroke 41: 1646-1651, 2010.

8. Xu X, Kriegel AJ, Liu Y, Usa K, Mladinov D, Liu H, Fang Y, Ding $X$ and Liang M: Delayed ischemic preconditioning contributes to renal protection by upregulation of miR-21. Kidney Int 82: 1167-1175, 2012.

9. Ji R, Cheng Y, Yue J, Yang J, Liu X, Chen H, Dean DB and Zhang C: MicroRNA expression signature and antisense-mediated depletion reveal an essential role of microRNA in vascular neointimal lesion formation. Circ Res 100: 1579-1588, 2007.

10. Guduric-Fuchs J, O'Connor A, Cullen A, Harwood L, Medina RJ, O'Neill CL, Stitt AW, Curtis TM and Simpson DA: Deep sequencing reveals predominant expression of miR-21 amongst the small non-coding RNAs in retinal microvascular endothelial cells. J Cell Biochem 113: 2098-2111, 2012.

11. Yasuda H, Yuen PS, Hu X, Zhou H and Star RA: Simvastatin improves sepsis-induced mortality and acute kidney injury via renal vascular effects. Kidney Int 69: 1535-1542, 2006.

12. Chen Y, Jiang S, Zou J, Zhong Y and Ding X: Silencing HIF-1a aggravates growth inhibition and necrosis of proximal renal tubular epithelial cell under hypoxia. Ren Fail 38: 1726-1734, 2016.

13. Jiao X, Xu X, Fang Y, Zhang H, Liang M, Teng J and Ding X: miR-21 contributes to renal protection by targeting prolyl hydroxylase domain protein 2 in delayed ischaemic preconditioning. Nephrology (Carlton) 22: 366-373, 2017.

14. Dharap A, Bowen K, Place R, Li LC and Vemuganti R: Transient focal ischemia induces extensive temporal changes in rat cerebral microRNAome. J Cereb Blood Flow Metab 29: 675-687, 2009.

15. Livak KJ and Schmittgen TD: Analysis of relative gene expression data using real-time quantitative PCR and the 2(-Delta Delta C(T)) method. Methods 25: 402-408, 2001.

16. Frankel LB, Christoffersen NR, Jacobsen A, Lindow M, Krogh A and Lund AH: Programmed cell death 4 (PDCD4) is an important functional target of the microRNA miR-21 in breast cancer cells. J Biol Chem 283: 1026-1033, 2007.

17. Eltzschig HK and Eckle T: Ischemia and reperfusion-from mechanism to translation. Nat Med 17: 1391-1401, 2011.

18. Rabelink TJ, Wijewickrama DC and de Koning EJ: Peritubular endothelium: The Achilles heel of the kidney? Kidney Int 72: 926-930, 2007.

19. Basile DP, Donohoe D, Roethe K and Osborn JL: Renal ischemic injury results in permanent damage to peritubular capillaries and influences long-term function. Am J Physiol Renal Physiol 281: F887-F899, 2001.

20. Yamamoto T, Tada T, Brodsky SV, Tanaka H, Noiri E, Kajiya F and Goligorsky MS: Intravital videomicroscopy of peritubular capillaries in renal ischemia. Am J Physiol Renal Physiol 282: F1150-F1155, 2002.

21. Snoeijs MG, Vink H, Voesten N, Christiaans MH, Daemen JW, Peppelenbosch AG, Tordoir JH, Peutz-Kootstra CJ, Buurman WA, Schurink GW and van Heurn LW: Acute ischemic injury to the renal microvasculature in human kidney transplantation. Am J Physiol Renal Physiol 299: F1134-F1140, 2010.

22. Horbelt M, Lee SY, Mang HE, Knipe NL, Sado Y, Kribben A and Sutton TA: Acute and chronic microvascular alterations in a mouse model of ischemic acute kidney injury. Am J Physiol Renal Physiol 293: F688-F695, 2007.

23. Leonard EC, Friedrich JL and Basile DP: VEGF-121 preserves renal microvessel structure and ameliorates secondary renal disease following acute kidney injury. Am J Physiol Renal Physiol 295: F1648-F1657, 2008.

24. Koo DD, Welsh KI, West NE, Channon KM, Penington AJ, Roake JA, Morris PJ and Fuggle SV: Endothelial cell protection against ischemia/reperfusion injury by lecithinized superoxide dismutase. Kidney Int 60: 786-796, 2001.

25. Xu X, Kriegel AJ, Jiao X, Liu H, Bai X, Olson J, Liang M and Ding X: miR-21 in ischemia/reperfusion injury: A double-edged sword? Physiol Genomics 46: 789-797, 2014. 
26. Qin Y, Yu Y, Dong H, Bian X, Guo X and Dong S: MicroRNA 21 inhibits left ventricular remodeling in the early phase of rat model with ischemia-reperfusion injury by suppressing cell apoptosis. Int J Med Sci 9: 413-423, 2012.

27. Buller B, Liu X, Wang X, Zhang RL, Zhang L, Hozeska-Solgot A, Chopp $\mathrm{M}$ and Zhang ZG: MicroRNA-21 protects neurons from ischemic death. FEBS J 277: 4299-4307, 2010.

28. Polytarchou C, Iliopoulos D, Hatziapostolou M, Kottakis F, Maroulakou I, Struhl K and Tsichlis PN: Akt2 regulates all Akt isoforms and promotes resistance to hypoxia through induction of miR-21 upon oxygen deprivation. Cancer Res 71: 4720-4731, 2011.

29. Cheng Y, Zhu P, Yang J, Liu X, Dong S, Wang X, Chun B, Zhuang $\mathrm{J}$ and Zhang $\mathrm{C}$ : Ischaemic preconditioning-regulated miR-21 protects heart against ischaemia/reperfusion injury via anti-apoptosis through its target PDCD4. Cardiovasc Res 87: 431-439, 2010

30. Godwin JG, Ge X, Stephan K, Jurisch A, Tullius SG and Iacomini J: Identification of a microRNA signature of renal ischemia reperfusion injury. Proc Natl Acad Sci USA 107: 14339-14344, 2010.

31. Jia P, Teng J, Zou J, Fang Y, Wu X, Liang M and Ding X: Xenon protects against septic acute kidney injury via miR-21 target signaling pathway. Crit Care Med 43 e250-e259, 2015.
32. Qi L, Bart J, Tan LP, Platteel I, Sluis Tv, Huitema S, Harms G, Fu L, Hollema $\mathrm{H}$ and Berg Av: Expression of miR-21 and its targets (PTEN, PDCD4, TM1) in flat epithelial atypia of the breast in relation to ductal carcinoma in situ and invasive carcinoma. BMC Cancer 9: 163, 2009.

33. Jiang S, Chen Y, Zou J, Xu X, Zhang X, Liu C, Fang Y and Ding X: Diverse effects of ischemic pretreatments on the long-term renal damage induced by ischemia-reperfusion. Am J Nephrol 30: 440-449, 2009.

34. Yin C, Salloum FN and Kukreja RC: A novel role of microRNA in late preconditioning: Upregulation of endothelial nitric oxide synthase and heat shock protein 70. Circ Res 104: 572-575, 2009.

35. Dong S, Cheng Y, Yang J, Li J, Liu X, Wang X, Wang D, Krall TJ, Delphin ES and Zhang C: MicroRNA expression signature and the role of microRNA-21 in the early phase of acute myocardial infarction. J Biol Chem 284: 29514-29525, 2009.

36. Weber M, Baker MB, Moore JP and Searles CD: MiR-21 is induced in endothelial cells by shear stress and modulates apoptosis and eNOS activity. Biochem Biophys Res Commun 393: 643-648, 2010.

37. Sabatel C, Malvaux L, Bovy N, Deroanne C, Lambert V, Gonzalez ML, Colige A, Rakic JM, Noël A, Martial JA and Struman I: MicroRNA-21 exhibits antiangiogenic function by targeting RhoB expression in endothelial cells. PLoS One 6: e16979, 2011 